\title{
Risk Communication, Values Clarification, and Vaccination Decisions
}

\author{
Holly O. Witteman, ${ }^{1,2,3, *}$ Selma Chipenda Dansokho, ${ }^{2}$ Nicole Exe, ${ }^{4}$ Audrey Dupuis, ${ }^{5}$ \\ Thierry Provencher, ${ }^{6}$ and Brian J. Zikmund-Fisher ${ }^{4,7,8,9}$
}

\begin{abstract}
Many health-related decisions require choosing between two options, each with risks and benefits. When presented with such tradeoffs, people often make choices that fail to align with scientific evidence or with their own values. This study tested whether risk communication and values clarification methods could help parents and guardians make evidencebased, values-congruent decisions about children's influenza vaccinations. In 2013-2014 we conducted an online $2 \times 2$ factorial experiment in which a diverse sample of U.S. parents and guardians $(n=407)$ were randomly assigned to view either standard information about influenza vaccines or risk communication using absolute and incremental risk formats. Participants were then either presented or not presented with an interactive values clarification interface with constrained sliders and dynamic visual feedback. Participants randomized to the risk communication condition combined with the values clarification interface were more likely to indicate intentions to vaccinate $(\beta=2.10, t(399)=2.63, p<0.01)$. The effect was particularly notable among participants who had previously demonstrated less interest in having their children vaccinated against influenza $(\beta=-2.14, t(399)=-2.06, p<0.05)$. When assessing vaccination status reported by participants who agreed to participate in a follow-up study six months later $(n=116)$, vaccination intentions significantly predicted vaccination status $(\mathrm{OR}=1.66,95 \% \mathrm{CI}(1.13,2.44), p<0.05)$ and rates of informed choice $(\mathrm{OR}=1.51,95 \% \mathrm{CI}$ $(1.07,2.13), p<0.012)$, although there were no direct effects of experimental factors on vaccination rates. Qualitative analysis suggested that logistical barriers impeded immunization rates. Risk communication and values clarification methods may contribute to increased vaccination intentions, which may, in turn, predict vaccination status if logistical barriers are also addressed.
\end{abstract}

KEY WORDS: Children; immunization; influenza; interface design; risk communication methods; vaccination; values clarification exercise; values clarification methods; values congruence

${ }^{1}$ Department of Family and Emergency Medicine, Faculty of Medicine, Laval University, Quebec City, Quebec, Canada.

${ }^{2}$ Office of Education and Continuing Professional Development, Faculty of Medicine, Laval University, Quebec City, Quebec, Canada.

${ }^{3}$ Research Centre of the CHU de Québec, Quebec City, Quebec, Canada.

${ }^{4}$ Center for Bioethics and Social Sciences in Medicine, University of Michigan, Ann Arbor, MI, USA.

${ }^{5}$ Department of Information and Communication, Laval University, Quebec City, Quebec, Canada.
${ }^{6}$ Department of Psychology, Laval University, Quebec City, Quebec, Canada.

${ }^{7}$ Department of Health Behavior and Health Education, School of Public Health, University of Michigan, Ann Arbor, MI, USA.

${ }^{8}$ Department of Internal Medicine, University of Michigan, Ann Arbor, MI, USA.

${ }^{9}$ Risk Science Center, School of Public Health, University of Michigan, Ann Arbor, MI, USA.

*Address correspondence to Holly O. Witteman, Faculté de médecine, Pavillon Ferdinand-Vandry 2881-F, Université Laval, Québec (QC), Canada, G1V 0A6; tel: 418.656.2131×3981; holly.witteman@fmed.ulaval.ca. 


\section{INTRODUCTION}

Many choices in the context of health require choosing between two options in which both carry an element of risk. When presented with such risk tradeoffs, people can make choices that run contrary to their preferences and values. These types of inconsistencies are especially apparent when probabilities are small and when risks are laden with emotion. ${ }^{(1,2)}$ Previous research has documented this effect in multiple studies, ${ }^{(3,4)}$ demonstrating that this difficulty in making an evidence-based and values-congruent decision is a robust and persistent phenomenon. By values-congruent, we mean choices that align with people's stated values.

Health decision support tools such as patient decision aids can support informed choices and increased clarity of values. ${ }^{(5)}$ However, more research is needed on methods of shared decisionmaking ${ }^{(6)}$ that can not only help people better understand risks and benefits, but also how their values relevant to those risks and benefits determine what choice might be best suited to them. Previous research has demonstrated that particular design features of risk visualizations and interactive online interfaces can help people make more values-congruent choices when faced with risk tradeoffs. ${ }^{(7,8)}$ For example, in the context of a hypothetical treatment for colon cancer, by using an interactive interface that makes the tradeoffs of a decision apparent and explicitly shows people how their stated preferences imply that one option is more in line with their values than the other, the proportion of study participants who made incongruent choices was reduced by $40 \% .{ }^{(9)}$

In the present study, we applied similar methods to vaccination decisions. Decisions about immunization may be complex and involve many influences, ${ }^{(10)}$ including omission bias, meaning that people feel more regret about a negative outcome from something they elected to do than from something they elected not to do, ${ }^{(11)}$ complex mental models, ${ }^{(12)}$ social networks, ${ }^{(13)}$ social norms derived from increasingly polarized online social groups, ${ }^{(14,15)}$ and other media influences ${ }^{(16-18)}$ that may contribute to vaccine hesitancy in developed countries. ${ }^{(19)}$ Such vaccine hesitancy may, in turn, be contributing to population health outcomes such as outbreaks of vaccine-preventable diseases ${ }^{(20)}$ and to individual health outcomes such as an increased rates of seizures in children. ${ }^{(21)}$
Childhood influenza immunization offers an interesting and important study context. Influenza vaccines first began to be recommended for healthy children aged 6 to 23 months in the United States in the 2004-2005 season. In the following years, the recommendations expanded by age groups until the vaccine was recommended in the 2008-2009 season for all children, aged 6 months to 17 years. ${ }^{(22)}$ In 2012, approximately half the children in the United States were vaccinated against influenza; yet $90 \%$ of deaths occurred among unvaccinated children. Approximately $40 \%$ of the children who died had no known health concerns. ${ }^{(23)}$ In addition to the need to reduce mortality and burden of illness among children, increased immunization of children could also reduce the burden of influenza in the population as a whole. ${ }^{(24)}$

Unlike some other health decisions, public information about influenza immunization does not typically include understandable numerical risk estimates (e.g., see information for the public from the Centers for Disease Control and Prevention). ${ }^{(25)}$ It can be difficult even for highly numerate people to develop a clear, well-informed sense of the overall risk-benefit balance. Parental concerns about the effectiveness and potential side effects of influenza vaccines have been noted as key reasons for choosing not to have their children vaccinated against influenza, ${ }^{(26,27)}$ making the lack of clear, comprehensible information an important concern.

Furthermore, relatively little work has been done to help parents and guardians understand how immunization decisions for their children relate to their parental values. The process of values clarification, that is, of sorting out what is important to an individual relevant to a decision, ${ }^{(28)}$ is a key step in making an informed choice. ${ }^{(29)}$ By informed choice we mean a decision that meets key criteria of normative frameworks of health decision quality. Specifically, the decision must be based on relevant knowledge, be aligned with the values of the decisionmaker, and be behaviorally implemented, meaning that the decisionmaker follows through on the decision. ${ }^{(30,31)}$ There is a need to better bridge the information available to parents because information sources that are critical of vaccines tend to focus more on values, while official information sources focus more on communicating about risks and benefits. ${ }^{(12)}$ 
The overall objective of this study was to better understand how to help people make more informed choices when presented with risk-benefit tradeoffs. To pursue this aim, we used an experimental design to test methods that might help parents understand the risks associated with immunizing and not immunizing their children against influenza, grasp the tradeoffs inherent in the decision, visualize how their individual values relate to their options, and make choices that align with their values. Available statistics about the risks and benefits of flu vaccines-for example, the fact that, in the 20122013 flu season, $90 \%$ of influenza-related pediatric deaths occurred among unvaccinated children ${ }^{(23)}-$ suggest that, for most parents, the benefits of children's influenza immunization outweigh the risks. Therefore, by helping people understand the different statistics for vaccinated and unvaccinated children and also guiding them through the process of aligning their choices with their values relevant to the decision, we hypothesized that we would observe higher intentions among participants to vaccinate their children against influenza and thus higher rates of vaccination.

\section{METHODS}

\subsection{Recruitment}

During the months of November and December 2013, we invited members of Amazon's Mechanical Turk (MTurk) ${ }^{(32)}$ to take an online survey about flu vaccines for children. To be eligible in the study, participants had to live in the United States, be 18 years or older, and be a parent or guardian who makes medical decisions for at least one child aged 6 months to 18 years. In addition, their child could not yet have received a flu vaccine in the current flu season nor could the child have medical reasons to avoid such a vaccine. In other words, both through timing and through inclusion and exclusion criteria, we targeted parents of children who were likely to be undecided about vaccinating their children against influenza. Participants were compensated $\$ 0.50$ for completing the first survey.

In June 2014, after flu season had ended, we invited participants who had completed the first survey to complete a follow-up survey. To recruit participants to the follow-up study, we sent a bonus payment $(\$ 0.10)$ along with a message inviting them to complete a brief follow-up questionnaire. After one week, we sent a single reminder to those who had yet to reply, along with a small additional bonus payment $(\$ 0.01)$. Participants who completed the follow-up questionnaire were therefore compensated between $\$ 0.60$ and $\$ 0.61$, bringing the total compensation across both surveys to between $\$ 0.60$ or $\$ 0.61$ (for participants who completed only the first survey and received the follow-up invitation and bonus payment) and $\$ 1.10$ or $\$ 1.11$ (for participants who completed the follow-up survey).

The study was deemed exempt by the Institutional Review Board as anonymous survey research. Before clicking to begin both the original and followup survey, all participants viewed a consent page in which they were informed that the survey would involve learning about flu vaccines for children. The consent page included an explicit statement to the effect that the study was not funded by or associated with any pharmaceutical company, and that we were interested in participants' honest opinions.

\subsection{Design of Experiment}

We conducted a $2 \times 2$ factorial experiment. The first factor, Risk Communication, randomly varied between a Control condition, for which we presented standard information about influenza immunization copied directly from the Centers for Disease Control and Prevention with their formatting, ${ }^{(25)}$ and a Risk Communication condition, in which we presented numerical information and graphics showing absolute risk estimates of the risks and benefits of flu vaccines for children, including rates of pediatric deaths in 2012-2013 due to influenza and side effects of flu vaccines among children in the United States. We also described each benefit or risk briefly, for example, explaining Guillain-Barré Syndrome and its typical progression as simply and clearly as possible. We derived our estimates from published models and epidemiological studies. ${ }^{(23,33-35)}$ As much as possible, we based our calculations on publications that were freely available (meaning not behind paywalls) in order to facilitate transparency. For participants randomized to the Risk Communication condition, we provided links to our sources after participants had completed the survey. Estimates were presented as rates per 10 million children; we further contextualized this number by informing participants that there are approximately 65 million children in the United States. Using a consistent denominator helps people better understand and compare risk estimates. ${ }^{(36)}$ When presenting data about children's deaths due to 
influenza, we also included icon arrays ${ }^{(7)}$ to help participants better understand the differences in death rates between groups of vaccinated and unvaccinated children. We presented the benefits of the pediatric influenza vaccine first (that is, avoiding the risks of influenza disease) followed by the risks of the vaccine. Specifically, we first presented tables of numbers for both vaccinated and unvaccinated children, for example: "Out of every 10 million children vaccinated against the flu, about 86 will be hospitalized because of the flu or its complications. Out of every 10 million children NOT vaccinated against the flu, about 367 will be hospitalized because of the flu or its complications" (emphasis in original). These were followed by summaries in which we calculated the differences for participants, e.g.: "For every 10 million children who are vaccinated against the flu, about 281 children will avoid being hospitalized because of the flu or its complications" (emphasis in original). This technique, in which we do the arithmetic for people to highlight the incremental risk difference, has been associated with better outcomes in other decision contexts. ${ }^{(8,37)}$ After presenting the benefits and risks separately, we presented a summary table of incremental benefits and risks side by side. The full presentation can be seen in Appendix 1 .

The second factor, Values Clarification, randomly varied between a control condition (No Values Clarification condition) and a Values Clarification condition in which participants were asked to use sliders to indicate the importance of competing risks, such as avoiding death due to flu and avoiding a serious complication such as Guillain-Barré Syndrome from the vaccine. This use of the term Values Clarification represents the current definition in use in the field of shared decisionmaking. ${ }^{(38)}$ The sliders were constrained such that as a participant moved one slider in one direction, the other automatically moved in the other direction, making the tradeoffs in the decision explicit and salient. We also displayed a recommended option via vertical bars that moved dynamically based on a simple linear function of the slider positions. See Fig. 1 for an image of the Values Clarification interface.

\subsection{Study Procedure}

Participants began the study by reading about influenza. Following this general information, they were exposed to either the Control or Risk Communication presentation of information. Participants who had been randomized to the Values
Clarification condition were then asked to complete a brief values clarification exercise, whereas those randomized to No Values Clarification proceeded directly to the portion of the survey in which we assessed outcomes. (See Fig. 2 for a study flow diagram.) We then collected participants' responses to our primary outcome, followed by other questions that included a secondary outcome, moderator and sociodemographic questions. We asked participants to think of their child when answering the questions. Participants with more than one child within the eligible age range were randomly instructed to think of their child who had either the earliest or latest birthday in the calendar year.

At the conclusion of the survey, participants were provided with a brief list of resources for learning more about flu vaccines, including where they could get their child vaccinated.

Approximately six months later, after flu season had finished, people who participated in the followup study were asked whether or not they got their child vaccinated. We also asked them for their opinion about the risk-benefit balance of influenza immunization, to briefly state why they did or did not get their child vaccinated, and to answer questions that assessed their retained gist knowledge ${ }^{(39)}$ about the risks and benefits of flu vaccines.

\subsection{Measures}

\subsubsection{Independent Variables}

There were two independent variables in the experimental design, as described in the previous section. The variable Risk Communication describes whether study participants were presented with absolute risk and benefit estimates of influenza immunization for children (Risk Communication condition) or standard information copied directly from the website of the Centers for Disease Control (Control condition). The variable Values Clarification describes whether or not participants were asked to complete a values clarification exercise designed to help them clarify what is important to them and align their decision with their values (Values Clarification condition vs. No Values Clarification condition).

\subsubsection{Primary Proximal Outcome (Original Survey): Vaccination Intentions}

The primary outcome in this study was Vaccination Intentions, a measure of participants' intentions 
what matters to me

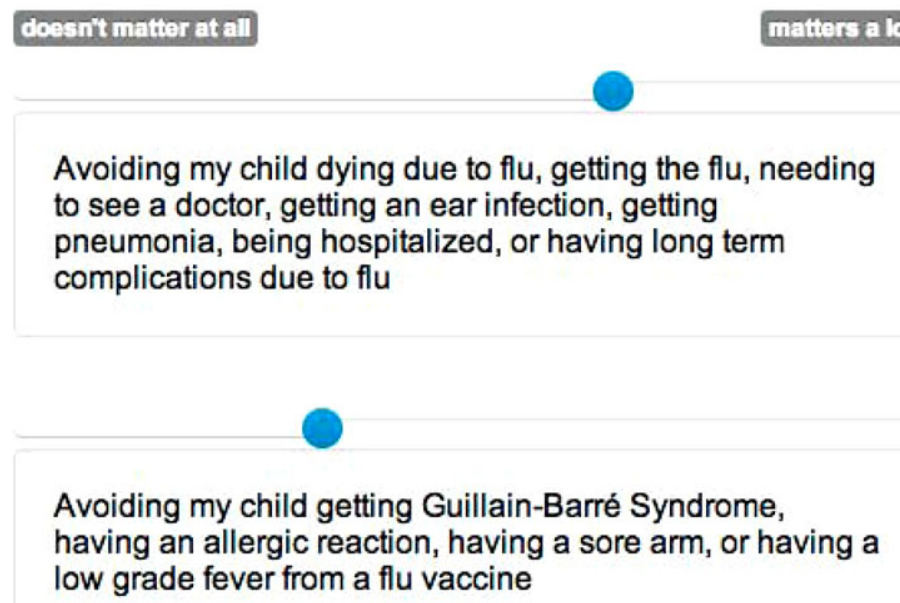

\section{what's best for me}
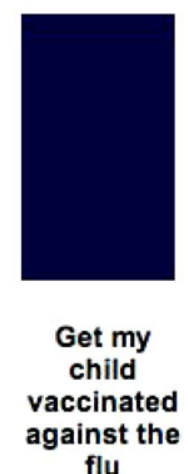

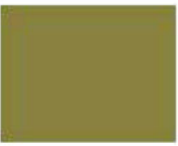

Don't get my child vaccinated against the flu

Fig. 1. Values clarification interface.

to vaccinate their child against influenza. The introductory text for this outcome read: "You may or may not have made a decision about whether or not to get a flu vaccine for your child this year. We would like to know your feelings about this decision at this moment." Participants were then asked to respond to the question, "Based on how you feel about this decision right now, would you say you will choose to," on a nine-point Likert scale, with anchors, "Definitely GET my child a flu vaccine this year," (value 4) on the left of the scale and, "Definitely NOT get my child a flu vaccine this year," (value -4 ) on the right (capitalization in original). Participants did not see the numbers associated with the response options, only a row of radio buttons.

\subsubsection{Primary Distal Outcome (Follow-Up Survey): Vaccination Status}

For the subset of participants who completed the follow-up survey, we also collected a primary distal outcome: Vaccination Status. Participants were asked: "In our original survey in November/ December 2013, we gave you information about flu vaccines for children and asked you whether or not you thought you would get a flu vaccine for your child. Please tell us: Did your child get a flu vaccine since you took the last survey in November/ December 2013?" Response options were, "Yes," "No," or "Not sure/Can't remember." Parental report about children's influenza vaccination status is an imperfect but acceptably valid measure of such status, particularly in a study such as ours, which occurred entirely online. Previous studies have documented the sensitivity and specificity of self-report in this context as $88 \%$ and $90 \%$ in one study $^{(40)}$ and as $91 \%$ and $82 \%$ in another. ${ }^{(41)}$

\subsubsection{Secondary Outcome (Original Survey): Values Congruence}

We also considered a secondary outcome in this study: Values Congruence. To assess this, near the end of the first survey, we asked all participants a question based on previous research about attitudes in the United States about childhood vaccination, ${ }^{(42)}$ "Which of the following statements best represents your opinion (choose one): When it comes to flu vaccines for children ..." with five possible response options, "The benefits of the vaccine strongly outweigh the risks," "The benefits of the vaccine slightly outweigh the risks," "The benefits and risks of the vaccine are about equal," "The risks of the vaccine slightly outweigh the benefits," or "The risks of the vaccine strongly outweigh the benefits."

To measure participants' values congruence, we compared their response about the risk-benefit balance to their vaccination intentions and noted each participant's responses as either congruent or not. We assigned the top two points on the vaccination intentions scale (top point $=$ definitely get my child the vaccine) as indicating strong intentions toward 


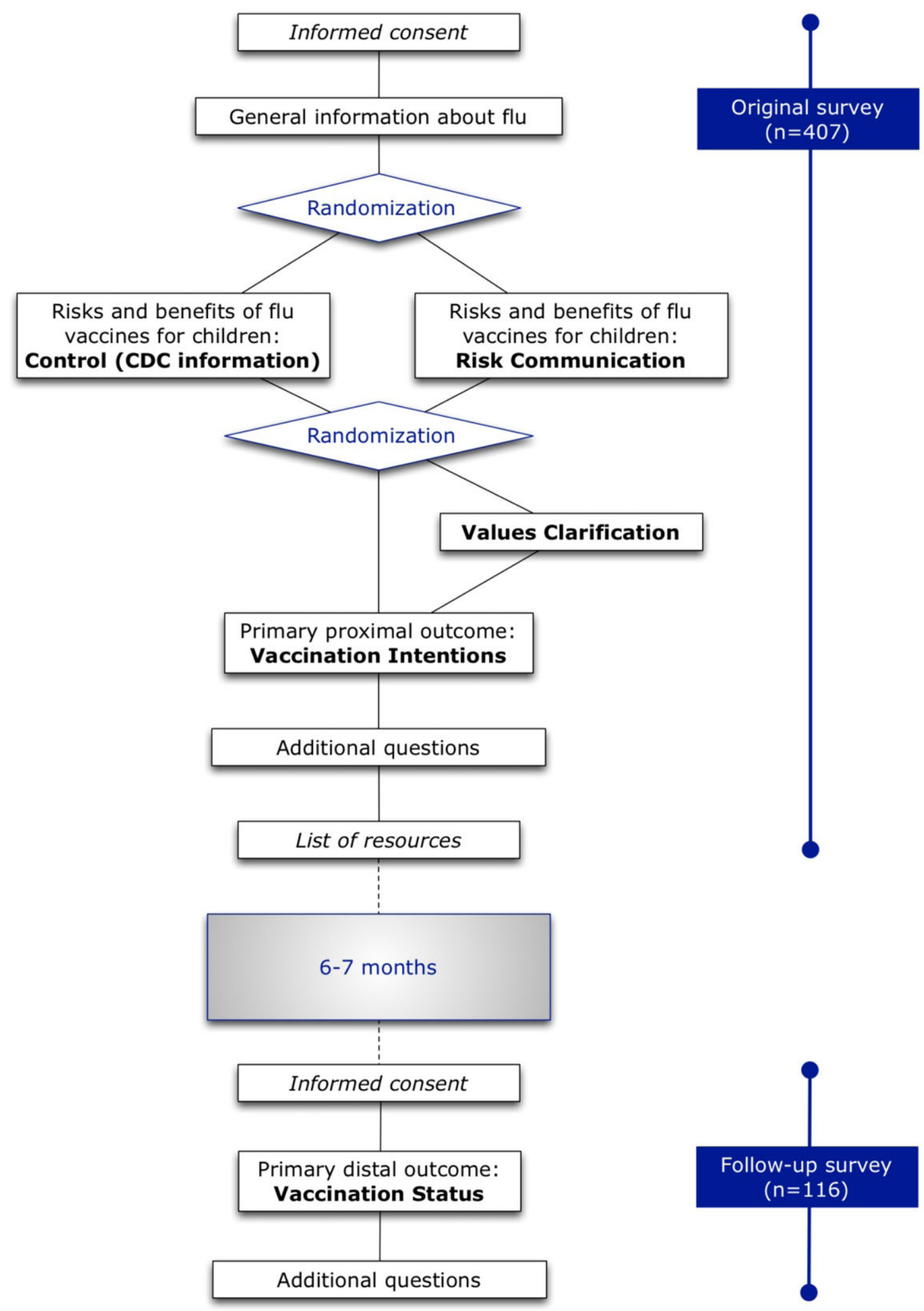

Fig. 2. Study flow. 
vaccination and thus congruent with the first risk-benefit balance statement (benefits strongly outweigh risks), the third and fourth top points as indicating weak intentions toward vaccination and thus congruent with the second statement (benefits slightly outweigh risks), the middle point of the vaccination intentions measure as indicating neutrality and thus congruent with the third statement (benefits and risks about equal), the sixth and seventh points as indicating weak intentions against vaccination and thus congruent with the fourth statement (risks slightly outweigh benefits), and the bottom two points on the vaccination intentions scale (bottom point $=$ definitely not get my child the vaccine) as indicating strong intentions against vaccination and thus congruent with the fifth statement (risks strongly outweigh benefits).

\subsubsection{Secondary Outcome (Follow-Up Survey): Informed Choice}

We used a measure of informed choice according to the framework developed by Marteau, Dormandy, and Michie, ${ }^{(30,31)}$ which stipulates that an informed choice must satisfy three criteria. First, it must be based on an adequate understanding of relevant knowledge. Second, it must be aligned with the values of the decisionmaker. Third, it must be behaviorally implemented, meaning that the person follows through on the decision and implements the action chosen. We collected data about participants' knowledge only in the follow-up survey to avoid a knowledge test influencing the effects of the intervention in the original study.

To assess knowledge, we listed each of the 11 risks and benefits that had been presented in the original study and asked participants to indicate whether they thought each event was "more likely for children who are vaccinated against flu, just as likely for all children, whether or not they are vaccinated against flu, or more likely for children who are NOT vaccinated against flu" (capitalization original). Although we collected data for all 11 items, all of which had been clearly presented in the Risk Communication condition, for the measure of informed choice, we used only the four items that were explicitly presented in the Control condition. Participants who had three or four items correct (i.e., who were at or above the median number of correct answers) were deemed to have adequate knowledge. It should be noted that there was almost perfect overlap between the latter participants and those who scored at or above median on the 11 items, but we defined adequate knowledge based on the subset of four items to ensure that all participants had as fair a chance as possible to give correct answers. See Appendix 2 for the 11 items, with the subset of four items indicated.

To assess alignment with values, we used a similar approach as that for values congruence. Participants who had indicated in the original survey that they thought that the benefits of influenza vaccines strongly or somewhat outweighed the risks were classified as valuing vaccinating. Thus, the distinction between this measure and values congruence is that the latter is based on participants' decision intentions whereas the former is based on their actual decisions. Therefore, if such a participant indicated in the follow-up survey that he or she had gotten the participant's child vaccinated, we assessed that as a valuescongruent and behaviorally implemented decision. Participants who had indicated that they felt that the risks and benefits were equal, or that the risks outweighed the benefits somewhat or strongly, were classified as valuing not vaccinating. If these participants indicated that they had not gotten their child vaccinated, we assessed that as a values-congruent and behaviorally implemented decision.

We then defined participants who had made an informed choice as those who had adequate knowledge and who had made decisions that were both values-congruent and behaviorally implemented.

\subsubsection{Secondary Outcome (Follow-Up Survey): Reasons for Vaccinating or Not Vaccinating}

The third question in the follow-up survey was an open text field with the question wording: "Please tell us (briefly) why did your child did or did not get the flu vaccine. Remember: We are interested in your honest answers."

\subsubsection{Moderator: Decision History}

As an indicator of participants' overall attitudes toward flu vaccines for children, in the original survey, we asked about their decision history: "Which of the following statement best describes your decisions about flu vaccines for your child(ren) in the past 5 years? If you have not been a parent/guardian for at least 5 years, answer for the number of years you have been a parent/guardian," with response options, "I chose to get my child(ren) a flu vaccine every year," "I chose to give my child(ren) a flu vaccine some years," and, "I never chose to get my child(ren) 
a flu vaccine." For analyses, we combined the first two statements to create a dichotomous variable indicating whether or not the participant had previously demonstrated interest in immunizing his or her child(ren) against influenza.

\subsection{Analyses}

Analysis of the primary proximal outcome $\mathrm{Vacci}$ nation Intentions was conducted as a linear regression with both experimental factors as well as the moderator entered into the model. Values Congruence used the same model components but was analyzed as a logistic regression. Both distal outcomes, primary Vaccination Status and secondary Informed Choice, were analyzed via logistic regression with both experimental factors entered into the model as well as Vaccination Intentions as a moderator.

We conducted a thematic analysis of the responses to our question about why the participants had chosen to get or not to get their child vaccinated. Two authors (HOW, SCD) collaboratively developed the coding scheme and then independently thematically coded each response in Microsoft Excel, ${ }^{(43)}$ assigning one to three themes per response as needed. Discrepancies were resolved by discussion until we reached consensus. We summarized the frequency of each theme and compared frequencies of themes between participants who chose to vaccinate and those who chose not to vaccinate their child. We also analyzed frequencies of themes for parents and guardians who chose to have or not to have their child vaccinated against influenza compared to their previously stated intentions in the original survey. We conducted these analyses via Fisher's exact tests due to the presence of cells in the contingency tables with frequencies less than 5 .

In all regressions, we examined all potential main effects and interactions. The alpha level for primary outcomes was 0.05 . For the four analyses of secondary variables, we applied a Bonferroni correction to reduce the likelihood of family-wise type 1 error, resulting in an alpha level of 0.012 for these outcomes. All analyses were conducted in R, version 3.0.2.(44)

\section{RESULTS}

\subsection{Study Participants}

Of the 666 people who clicked on the survey and answered the eligibility questions, 579 were eligible to participate in the study. Of these, 412 (71\%) completed the survey. The median time to complete the full survey was 14 minutes (interquartile range 10-19 minutes). We excluded from analysis participants who completed the full survey in less than 5 minutes, as this speed suggested that they might not have been paying attention to the content. Five participants were excluded on this basis. Thus, the final sample for analysis comprised responses from 407 participants ( $70 \%$ of eligible participants).

Participants were predominantly female and half of participants were between the ages of 28 and 41. Participants' ethnicities and races were diverse, though not completely representative of the U.S. population. Nearly half had no college degree. See Table I for details of study participant characteristics.

We invited 406 of the original 407 participants to participate in the follow-up survey. One participant was excluded because he or she had not entered a code in the original survey that would allow us to link responses between the two surveys for that participant. Of the 406 people invited, $116(29 \%)$ completed the follow-up survey. They were generally representative of the original group. The only characteristic that showed any lack of representativeness was age: participants who completed the follow-up survey were slightly older as a group (mean age 37, $S D$ 9) compared to those who did not (mean age 35, $S D$ 9, $\beta=2.99, t(405)=4.92, p<0.05)$. See Table I for further details.

A randomization check showed that nearly all of the various participant characteristics were evenly distributed across the experimental factors $(p s>$ 0.05). However, one characteristic demonstrated unbalanced distribution. Participants who identified as Asian or Asian American were unequally divided on the Values Clarification factor. In the first survey, three of these participants were randomized to the Values Clarification condition; the remaining 15 were not (Fisher's exact test: odds ratio 5.4, 95\% CI $(1.5,29.5), p<0.05)$. Similarly, in the follow-up study, a randomization check showed that all six participants who identified as Asian or Asian American came from the group of 15 who were not randomized to Values Clarification (Fisher's exact test $p<0.05$ ). As these participants represented a fraction of our sample and race was not a planned moderating factor in our analyses, this imbalance did not change our analytical approach. Although participants who completed the follow-up study were, as indicated above, older as a group, their ages did not vary significantly between the study arms to which they had originally 
Table I. Study Participant Characteristics

\begin{tabular}{|c|c|c|c|c|}
\hline \multicolumn{2}{|l|}{ Characteristic } & $\begin{array}{l}\text { Main Survey } \\
\quad(N=407)\end{array}$ & $\begin{array}{l}\text { Follow-Up Survey } \\
\qquad(N=116)\end{array}$ & $\begin{array}{l}\text { Test of } \\
\text { Differences } \\
(\text { Note } 1)\end{array}$ \\
\hline \multicolumn{5}{|c|}{ Sociodemographic Characteristics of Participants } \\
\hline \multicolumn{2}{|c|}{ Age: Mean $(S D)$} & $35(9)$ & $37(9)$ & $p<0.05$ \\
\hline \multirow[t]{2}{*}{ Gender: $N(\%)$} & Female & $257(63 \%)$ & $71(61 \%)$ & ns \\
\hline & Male & $149(37 \%)$ & $45(39 \%)$ & \\
\hline \multirow[t]{2}{*}{ Ethnicity: $N(\%)$} & Hispanic & $33(8 \%)$ & $5(4 \%)$ & ns \\
\hline & Middle Eastern & $1(0.2 \%)$ & $0(0 \%)$ & ns \\
\hline \multirow[t]{6}{*}{ Race: $N(\%)$} & African American or black & $42(10 \%)$ & $12(10 \%)$ & ns \\
\hline & American Indian or Alaska Native & $11(3 \%)$ & $1(1 \%)$ & ns \\
\hline & Asian or Asian American & $18(4 \%)$ & $6(5 \%)$ & ns \\
\hline & $\begin{array}{l}\text { Pacific Islander or Native } \\
\text { Hawaiian }\end{array}$ & $0(0 \%)$ & $0(0 \%)$ & ns \\
\hline & White or Caucasian & $324(80 \%)$ & $94(81 \%)$ & ns \\
\hline & Other & $5(1 \%)$ & $0(0 \%)$ & $\mathrm{ns}$ \\
\hline \multirow{10}{*}{$\begin{array}{l}\text { Highest education level } \\
\text { reached: } N(\%)\end{array}$} & None & $0(0 \%)$ & $0(0 \%)$ & ns (Note 2) \\
\hline & Elementary school & $0(0 \%)$ & $0(0 \%)$ & \\
\hline & Some high school, but no diploma & $6(1 \%)$ & $2(2 \%)$ & \\
\hline & High school (diploma or GED) & $42(10 \%)$ & $9(8 \%)$ & \\
\hline & Trade school & $11(3 \%)$ & $1(1 \%)$ & \\
\hline & Some college, but no degree & $133(33 \%)$ & $30(26 \%)$ & \\
\hline & Associate's degree (AA, AS, etc.) & $58(14 \%)$ & $20(17 \%)$ & \\
\hline & Bachelor's degree (BS, BA, etc.) & $113(28 \%)$ & $36(31 \%)$ & \\
\hline & Master's degree (MA, MPH, etc.) & $35(9 \%)$ & $12(10 \%)$ & \\
\hline & $\begin{array}{l}\text { Doctoral/professional degree } \\
(\mathrm{PhD}, \mathrm{MD} \text {, etc.) }\end{array}$ & $9(2 \%)$ & $6(5 \%)$ & \\
\hline \multicolumn{5}{|l|}{ Characteristics of Child } \\
\hline \multirow[t]{4}{*}{ Age of child: $N(\%)$} & 6-23 months old & $70(17 \%)$ & $21(18 \%)$ & ns \\
\hline & $2-4$ years old & $114(28 \%)$ & $32(28 \%)$ & \\
\hline & $5-11$ years old & $140(34 \%)$ & $36(31 \%)$ & \\
\hline & $12-17$ years old & $83(20 \%)$ & $27(23 \%)$ & \\
\hline \multicolumn{5}{|l|}{ Previous Vaccination Decisions } \\
\hline \multirow[t]{5}{*}{ Child has received: $N(\%)$} & $\begin{array}{l}\text { All standard vaccines, on standard } \\
\text { schedule }\end{array}$ & $258(64 \%)$ & $76(66 \%)$ & ns \\
\hline & $\begin{array}{l}\text { Selected vaccines, on standard } \\
\text { schedule }\end{array}$ & $54(13 \%)$ & $16(14 \%)$ & \\
\hline & $\begin{array}{l}\text { All standard vaccines, on alternate } \\
\text { schedule }\end{array}$ & $23(6 \%)$ & $8(7 \%)$ & \\
\hline & $\begin{array}{l}\text { Selected vaccines, on alternate } \\
\text { schedule }\end{array}$ & $39(10 \%)$ & $10(9 \%)$ & \\
\hline & Not applicable (no vaccines) & $31(8 \%)$ & $5(4 \%)$ & \\
\hline \multirow{3}{*}{$\begin{array}{l}\text { In the past } 5 \text { years, participant } \\
\text { chose to get a flu vaccine for } \\
\text { her/his child: } N(\%)\end{array}$} & Every year & $80(20 \%)$ & $27(23 \%)$ & ns \\
\hline & Some years & $159(39 \%)$ & $47(41 \%)$ & \\
\hline & Never & $168(41 \%)$ & $42(46 \%)$ & \\
\hline \multicolumn{5}{|l|}{ Vaccine Access } \\
\hline \multirow{3}{*}{$\begin{array}{l}\text { Flu vaccine available for child } \\
\text { without any out-of-pocket } \\
\text { costs: } N(\%)\end{array}$} & Yes & $237(58 \%)$ & $69(59 \%)$ & ns \\
\hline & No & $84(21 \%)$ & $24(21 \%)$ & \\
\hline & Not sure & $85(21 \%)$ & $23(20 \%)$ & \\
\hline \multirow{3}{*}{$\begin{array}{l}\text { Participant knows where to get } \\
\text { the flu vaccine: } N(\%)\end{array}$} & Yes & $385(95 \%)$ & $108(94 \%)$ & ns \\
\hline & No & $13(3 \%)$ & $4(3 \%)$ & \\
\hline & Not sure & $8(2 \%)$ & $3(3 \%)$ & \\
\hline \multicolumn{5}{|c|}{ Other Individual Difference Measures } \\
\hline \multirow{2}{*}{\multicolumn{2}{|c|}{$\begin{array}{l}\text { Subjective numeracy (out of possible } 6 \text { to } 48 \text { ): Median (IQR) } \\
\text { Beliefs about medicines (out of possible } 8 \text { to } 40 \text { ): Median (IQR) }\end{array}$}} & $38(11)$ & $38(11)$ & ns \\
\hline & & $24(8)$ & $24(9)$ & ns \\
\hline
\end{tabular}

Note 1: Differences tested via linear regression (continuous variables), chi-squared tests (categorical variables with 5 or more participants per cell) or Fisher's exact tests (categorical variables for which one or more cells had fewer than 5 participants), comparing participants in original survey who did and did not participate in follow-up survey.

Note 2: Fisher's exact test with simulated $p$-value converging to $p=0.05$ after each of $10^{4}, 10^{5}$, and $10^{6}$ simulations. 
been randomly assigned, nor did age demonstrate any tendencies toward influencing any of the outcomes.

\subsection{Outcomes}

Analyzing participants' vaccination intentions, we observed a main effect of participants' decision history. This moderator predicted their intentions $(\beta$ $=2.51, t(399)=4.92, p<0.001)$, meaning that participants who had previously decided to vaccinate one or more children against influenza were more inclined to do so again. We also observed a two-way interaction between Risk Communication and Values Clarification in their association with Vaccination Intentions $(\beta=2.10, t(399)=2.63, p<0.01)$ in which neither the Risk Communication condition nor the Values Clarification condition alone appeared to increase intentions significantly; however, when combined together, they increased intentions from the control condition by nearly one point on the ninepoint scale (see Fig. 3A). In addition, we observed a three-way interaction between all three predictors $(\beta$ $=-2.14, t(399)=-2.06, p<0.05)$, which suggested that while Risk Communication alone was more or less sufficient to help people who had vaccinated their children against flu within the past five years choose to do so again, the combination of Risk Communication and Values Clarification was especially important for participants who had not recently vaccinated their children against influenza (see Fig. 3B).

Rates of values congruence varied according to the experimental and moderating factors, ranging from $34 \%$ to $64 \%$ of participants stating vaccination intentions that were congruent with their stated values (see Table II for details). Among the two groups of participants who had and who had not previously gotten their child vaccinated against flu, the highest rates of values congruence were observed in the Risk Communication and Values Clarification conditions. However, the rates of values congruence did not vary statistically significantly. We observed no main effects nor any interactions.

Examining children's vaccination status as reported in the follow-up survey, we observed that neither experimental factor demonstrated any effects, nor were there any significant interactions. However, the moderator in the model, Vaccination Intentions, showed a main effect $(\mathrm{OR}=1.66,95 \%$ CI $(1.13$, $2.44), p<0.05)$. Overall, 44 participants $(38 \%)$ reported having their child vaccinated against flu. During the same time period as this study, approximately
$25 \%$ of children who had yet to be vaccinated against flu in the United States received a vaccine. ${ }^{(45)} \mathrm{Al}-$ though the national rate offers some context for our findings, it is important to note that participants in this study were not a random sample and therefore, due to the strong potential for selection bias, these rates should not be directly compared against each other. Fig. 4 displays details of patterns of reported vaccination. As can be seen in the figure, even among participants with the strongest intentions to get their child vaccinated against influenza, nearly two in five did not follow through on that intention.

Overall, 45/116 (39\%) of participants made an informed choice. Similar to vaccination status, the only significant predictor of informed choice was previous vaccination intentions, which demonstrated a main effect in which stronger intentions toward vaccination were associated with increased rates of informed choice $(\mathrm{OR}=1.51,95 \% \mathrm{CI}(1.07,2.13), p<$ $0.012)$. See Table III for more details regarding informed choice.

Examining participants' free text responses to the question of why they chose to get their child vaccinated or not, we observed two broad themes: Beliefs and Logistics, with five and three subthemes, respectively. The theme Beliefs has to do with participants' beliefs about the vaccine, immunity, the flu, and how the decision to vaccinate their child or not might impact on different people. The theme Logistics has to do with circumstances in people's lives that may either facilitate or impede them from having their child vaccinated against flu. See Table IV for a full description of themes and subthemes, sample quotes, and frequencies of each theme and subtheme. Themes were not exclusive, meaning that a single response could be coded with multiple themes and subthemes. One hundred and twelve out of the 116 participants $(97 \%)$ provided a comment that was coded with at least one and up to three of our defined subthemes. Analyzing the frequencies of each theme, we observed that participants who did get their child vaccinated almost exclusively cited Beliefs as their reason to have their child vaccinated. Within this group, there were 39/43 participants $(91 \%)$ whose responses contained only the theme Beliefs, 2/43 participants $(5 \%)$ whose responses contained only the theme Logistics, and 2/43 participants $(5 \%)$ whose responses contained both themes. Among participants who did not get their child vaccinated, Beliefs remained the more frequent theme but the theme Logistics also appeared frequently. Within this group, there were $41 / 69$ participants $(59 \%)$ whose 


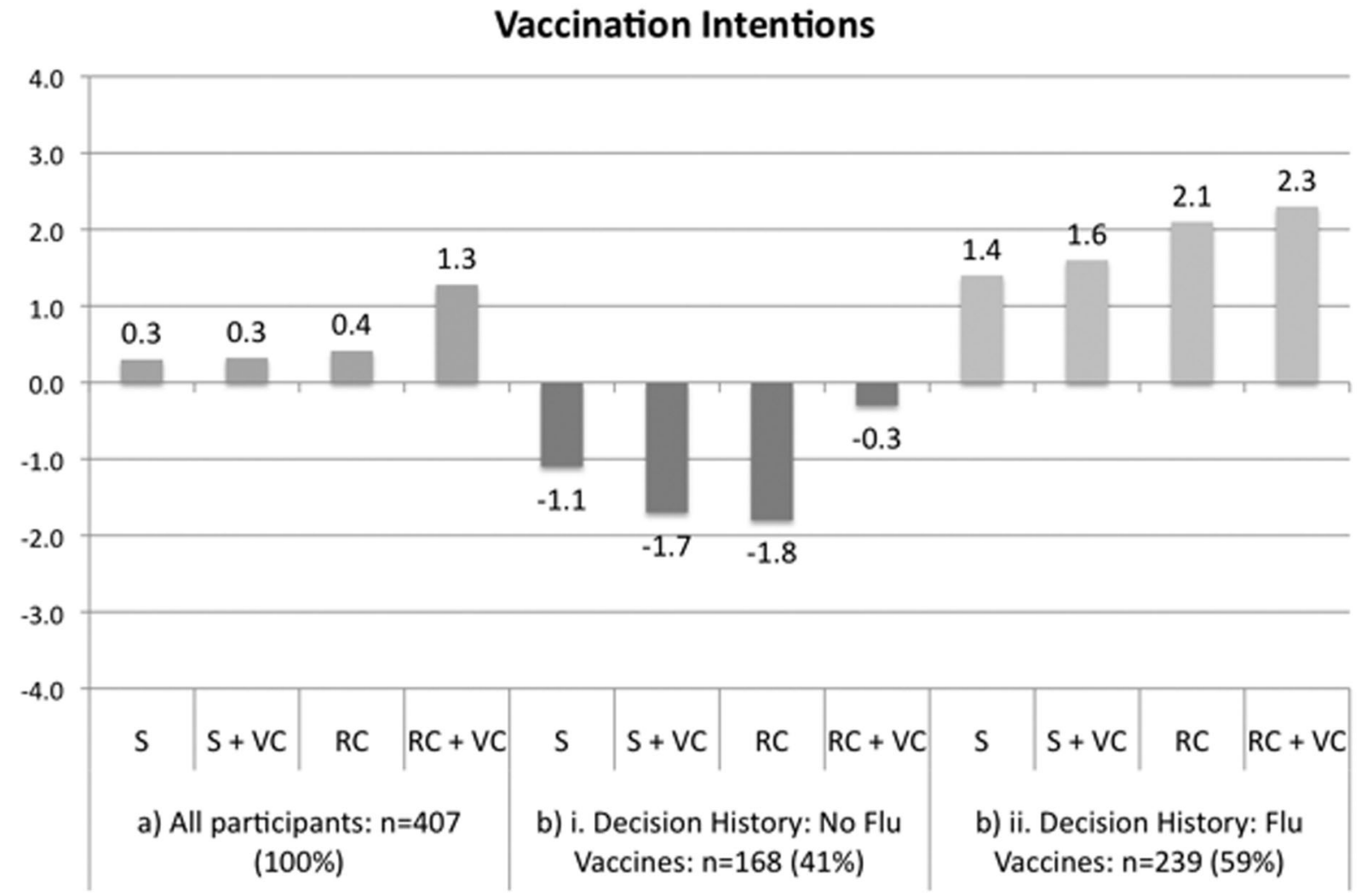

Fig. 3. Vaccination intentions by study arm and decision history.

$\mathrm{S}=$ standard risk presentation format $\mathrm{RC}=$ risk communication format $; \mathrm{VC}=$ values clarification interface.

Response scale ranged from 4 ("definitely GET my child a flu vaccine this year") to -4 ("definitely NOT get my child a flu vaccine this year")

Table II. Number of Participants with Values-Congruent Responses (Original Survey)

\begin{tabular}{lcccr}
\hline & $\mathrm{S}$ & $\mathrm{S}+\mathrm{VC}$ & $\mathrm{RC}$ & $\mathrm{RC}+\mathrm{VC}$ \\
\hline Decision History: No Flu Vaccines & $19 / 45(42 \%)$ & $12 / 35(34 \%)$ & $20 / 43(47 \%)$ & $22 / 45(49 \%)$ \\
Decision History: Flu Vaccines & $23 / 58(40 \%)$ & $31 / 55(56 \%)$ & $30 / 56(54 \%)$ & $45 / 70(64 \%)$ \\
\hline
\end{tabular}

$\mathrm{S}=$ standard risk presentation format $\mathrm{RC}=$ risk communication format; $\mathrm{VC}=$ values clarification interface.

responses contained only the theme Beliefs, 23/69 participants $(33 \%)$ whose responses contained only the theme Logistics, and 5/69 participants (7\%) whose responses contained both themes. Comparing people who did and did not have their child vaccinated, the patterns of theme frequencies were significantly different from each other (Fisher's exact $p<0.001$ ).

To incorporate participants' previously stated vaccination intentions into these analyses, we considered any participant who had marked one of the upper four points on the nine-point vaccination intentions scale as intending to vaccinate his or her child and any participant who indicated his or her intentions as neutral or lower as not intending to vaccinate the participant's child. Table $\mathrm{V}$ shows the distribution of themes among the groups whose actions did or did not align with their original intentions. All six participants who did not intend to vaccinate their child yet did so anyway indicated a reason that had to do with Beliefs. In contrast, among the 29 participants who did not vaccinate their child as intended, Logistics was the dominant theme. The patterns of theme frequencies 


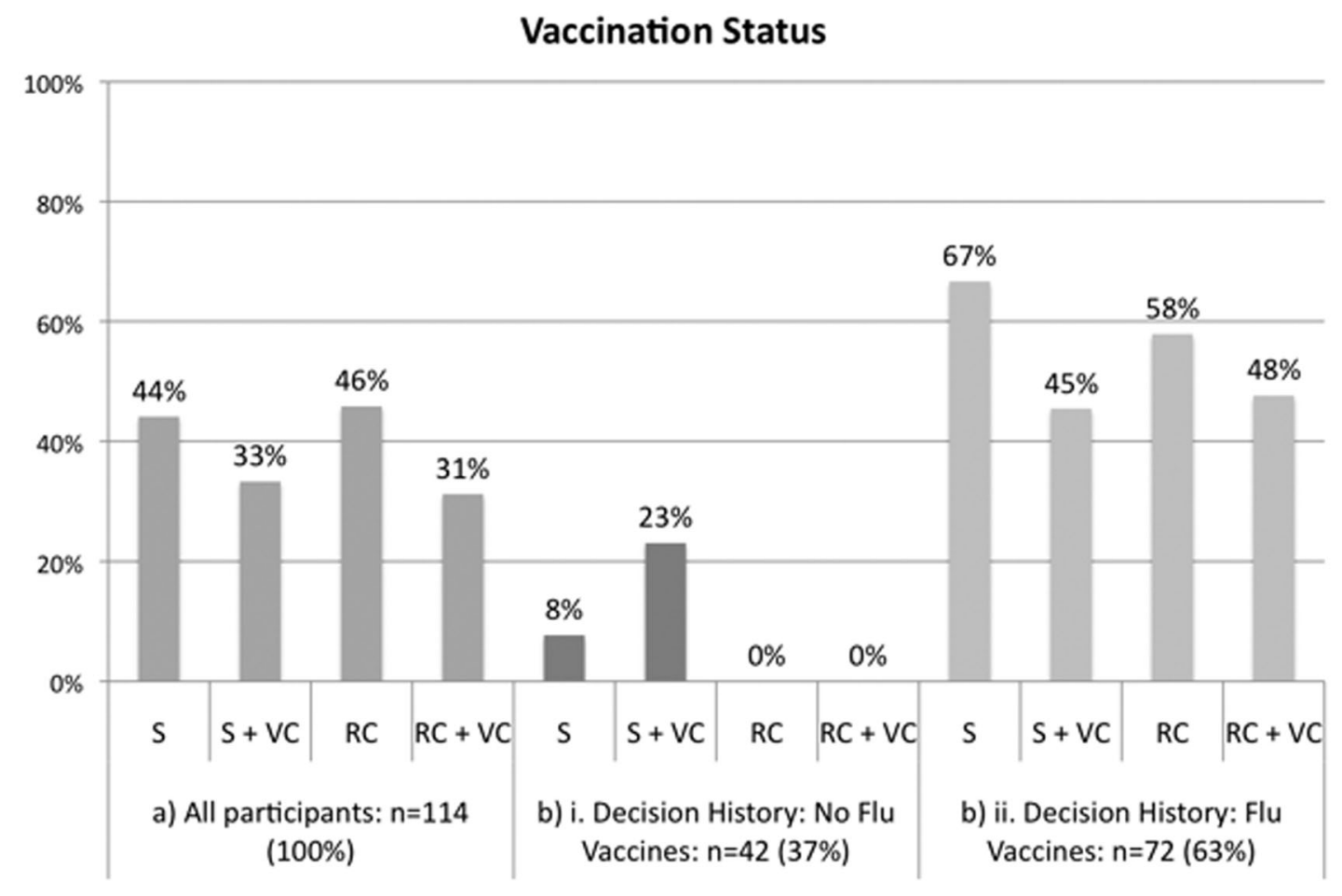

Fig. 4. Reported vaccination status by study arm and vaccination intentions.

$\mathrm{S}=$ standard risk presentation format $\mathrm{RC}=$ risk communication format; $\mathrm{VC}=$ values clarification interface.

differed significantly between groups (Fisher's exact $p<0.001)$.

\section{DISCUSSION}

\subsection{Principal Findings}

In this study, we examined the effects of risk communication methods that clearly present numerical estimates of the risks and benefits of influenza vaccines for children along with values clarification methods intended to help people understand which option is likely to be best aligned with what matters to them. Our results suggest that the combination of these two approaches is most effective for encouraging intentions to vaccinate, particularly for parents and guardians who may be more hesitant to vaccinate their children against influenza. The effects of our experimental factors did not directly influence vaccination rates in our small follow-up sample. However, our results demonstrated that vaccination intentions are associated with increased vaccination rates as well as rates of informed choice. Previous studies in the context of vaccination have demonstrated that vaccination intentions are associated with vaccination behaviors. ${ }^{(11)}$ Therefore, given that our experimental factors are associated with increased intentions, methods of risk communication and values clarification may be promising for further research about encouraging informed choice about vaccination.

Our results further demonstrated that while parents and guardians who initially had little to no intention to vaccinate their child against flu may sometimes change their mind in favor of vaccination, the primary gap between intentions and actions was among parents and guardians who intended to vaccinate their child but encountered logistical barriers such as access and affordability of vaccines. Future research will require more focus on the process and mechanisms of moving intentions into action in this context. For example, it has been demonstrated that adults make significant use of options to receive vaccines outside of medical clinics ${ }^{(46)}$ and clinic hours. ${ }^{(47)}$ Schools may serve as a similarly accessible site for children's vaccinations. ${ }^{(48)}$ Cost should not be ignored as a potential barrier; however, it should be noted that even when vaccines against influenza are widely available at no out-of-pocket cost to parents or guardians, uptake may remain low. ${ }^{(49)}$ 
Table III. Informed Choice (Follow-Up Survey)

\begin{tabular}{|c|c|c|c|}
\hline & \multicolumn{2}{|c|}{ Components of Informed Choice } & \multirow[b]{2}{*}{$\begin{array}{l}\text { Participants who made an } \\
\text { informed choice }\end{array}$} \\
\hline & $\begin{array}{l}\text { Participants with adequate } \\
\text { knowledge }\end{array}$ & $\begin{array}{c}\text { Participants who made } \\
\text { values-congruent, } \\
\text { behaviorally implemented } \\
\text { decisions }\end{array}$ & \\
\hline \multicolumn{4}{|l|}{ Overall $(n=116)$} \\
\hline & $72(62 \%)$ & $68(59 \%)$ & $45(39 \%)$ \\
\hline \multicolumn{4}{|l|}{ Study Arm } \\
\hline $\mathrm{S}(n=35)$ & $17(49 \%)$ & $24(69 \%)$ & $13(37 \%)$ \\
\hline $\mathrm{S}+\mathrm{VC}(n=24)$ & $13(54 \%)$ & $15(63 \%)$ & 7 (29\%) \\
\hline $\mathrm{RC}(n=25)$ & $22(88 \%)$ & $12(48 \%)$ & $12(48 \%)$ \\
\hline $\mathrm{RC}+\mathrm{VC}(n=32)$ & $20(63 \%)$ & $17(53 \%)$ & $13(40 \%)$ \\
\hline \multicolumn{4}{|l|}{ Vaccination Intentions } \\
\hline $\begin{array}{l}\text { Strong intentions against } \\
\text { vaccinating }(n=21)\end{array}$ & $8(38 \%)$ & $18(86 \%)$ & $6(29 \%)$ \\
\hline $\begin{array}{l}\text { Weak intentions against } \\
\text { vaccinating }(n=11)\end{array}$ & $3(27 \%)$ & $6(55 \%)$ & $1(9 \%)$ \\
\hline Neutral $(n=14)$ & $9(64 \%)$ & $6(43 \%)$ & $4(29 \%)$ \\
\hline $\begin{array}{l}\text { Weak intentions toward } \\
\text { vaccinating }(n=28)\end{array}$ & $20(71 \%)$ & $13(46 \%)$ & $11(39 \%)$ \\
\hline $\begin{array}{l}\text { Strong intentions toward } \\
\text { vaccinating }(n=42)\end{array}$ & $32(76 \%)$ & $25(60 \%)$ & $23(55 \%)$ \\
\hline
\end{tabular}

$\mathrm{S}=$ standard risk presentation format $\mathrm{RC}=$ risk communication format; $\mathrm{VC}=$ values clarification interface.

Similar to our findings, previous studies have demonstrated that patient decision aids designed to help parents and guardians make informed choices about routine childhood vaccines are associated with increased knowledge, reduced decisional conflict, ${ }^{(50,51)}$ more positive attitudes toward vaccination, ${ }^{(52)}$ and increased uptake of standard vaccines on the recommended schedule. ${ }^{(11)}$ These findings, together with ours, suggest that supporting parents and guardians in the process of making informed choices about vaccinating their children is a promising approach. In contrast, a recent study suggests that participatory decisionmaking may not be appropriate to the context of vaccination. The findings of this observational study of conversations between parents and health-care providers demonstrated that when health-care professionals linguistically framed whether or not to vaccinate as a decision to make (vs. a presumed action), parents were less likely to choose to vaccinate their children. ${ }^{(53)}$ However, this study did not include an analysis of whether or not health-care providers explicitly drew on parents' values to make recommendations, and the analysis did not distinguish between shared decisionmaking and leaving the decision wholly up to the parents or guardians with no decision-making participation on the part of the health-care provider.

Recommendations for health-care providers to address vaccine hesitancy are to educate parents more thoroughly about reasons to vaccinate their children, correct misinformation, and consider drawing on the power of narrative. ${ }^{(54,55)}$ A trial of a video- and text-based educational intervention for vaccine-hesitant parents that included personal accounts by parents whose children contracted vaccine-preventable diseases found that such an intervention was associated with more favorable attitudes toward vaccination-according to behavioral theory, a predictor of behavioral intentions ${ }^{(56)}$ _but also did not change behavior regarding standard childhood vaccines. ${ }^{(57)}$

Our study suggests that the combination of risk communication and values clarification methods designed specifically to support well-informed, values-congruent decisions may be particularly important when seeking to help vaccine-hesitant parents and guardians make fully informed decisions. We note that the risk communication methods did not clearly prioritize certain risks or benefits, and the values clarification method in this study 
Table IV. Themes (Follow-Up Survey)

\begin{tabular}{|c|c|c|c|c|}
\hline \multirow[b]{2}{*}{ Theme } & \multirow[b]{2}{*}{ Description } & \multirow[b]{2}{*}{ Sample quotes } & \multicolumn{2}{|c|}{ Theme frequency among: } \\
\hline & & & $\begin{array}{l}\text { Participants who } \\
\text { vaccinated their } \\
\text { child against flu } \\
\quad(n=44)\end{array}$ & $\begin{array}{c}\text { Participants who did } \\
\text { not vaccinate } \\
\text { their child against } \\
\text { flu }(n=70)\end{array}$ \\
\hline Beliefs & \multicolumn{2}{|c|}{$\begin{array}{l}\text { Comments that demonstrated the influence of the participant's beliefs, } \\
\text { feelings, or attitude on his or her decision to vaccinate or not vaccinate } \\
\text { the participant's child against flu }\end{array}$} & $41(93 \%)$ & $46(66 \%)$ \\
\hline Beliefs: child & $\begin{array}{l}\text { Beliefs about the } \\
\text { impact of } \\
\text { vaccinating or not } \\
\text { on the child }\end{array}$ & $\begin{array}{l}\text { Did not vaccinate: "I don't get the flu } \\
\text { vaccine for my children or myself } \\
\text { because in my own experience, getting } \\
\text { the vaccine has always made me actually } \\
\text { get the flu, so I don't want to have that } \\
\text { same thing happen for my children." } \\
\text { Vaccinated: "I did not want my child to } \\
\text { become ill and miss many school days." }\end{array}$ & $34(77 \%)$ & $35(50 \%)$ \\
\hline Beliefs: family & $\begin{array}{l}\text { Beliefs about the } \\
\text { impact the child's } \\
\text { vaccination status } \\
\text { on the family }\end{array}$ & $\begin{array}{l}\text { Vaccinated: "I have a large family, with a } \\
\text { lot of family gatherings. Some people in } \\
\text { my family have sensitive health issues. If } \\
\text { any of us gets the flu, we may endanger } \\
\text { someone else in the family. So we all get } \\
\text { shots." } \\
\text { Did not vaccinate: "They [vaccines] } \\
\text { genetically alter the person and can affect } \\
\text { that person's offspring." (this comment } \\
\text { also coded as Beliefs: child, and Beliefs: } \\
\text { vaccines \& immunity) }\end{array}$ & $9(20 \%)$ & $2(3 \%)$ \\
\hline Beliefs: others & $\begin{array}{l}\text { Beliefs about the } \\
\text { impact the child's } \\
\text { vaccination status } \\
\text { on others outside } \\
\text { the family }\end{array}$ & $\begin{array}{l}\text { Vaccinated: "I work in the healthcare } \\
\text { industry. All members of my family get } \\
\text { the flu vaccine every year. Because I } \\
\text { work with high risk patients, and there is } \\
\text { a chance that I might bring home the flu, } \\
\text { it makes sense to vaccinate. This provides } \\
\text { protection to my family, as well as } \\
\text { lowering the risk that I might bring an } \\
\text { illness to the patients that I work with on } \\
\text { a day to day basis." (this comment also } \\
\text { coded as Beliefs: family) }\end{array}$ & $2(5 \%)$ & $0(0 \%)$ \\
\hline Beliefs: flu & $\begin{array}{l}\text { Beliefs about } \\
\text { influenza, e.g., } \\
\text { what it is and how } \\
\text { serious it is }\end{array}$ & $\begin{array}{l}\text { Did not vaccinate: "The flu virus does not } \\
\text { appear to be that dangerous, an } \\
\text { inconvenience at most. Our child } \\
\text { generally hates doctors and medicines, so } \\
\text { it was just not that important." (this } \\
\text { comment also coded as Beliefs: child) } \\
\text { Vaccinated: "Both myself and my children } \\
\text { get them every single year. My kids have } \\
\text { never had any negative side effects. I had } \\
\text { the flu once and I would never want my } \\
\text { children to experience that." (this } \\
\text { comment also coded as Beliefs: child) }\end{array}$ & $8(18 \%)$ & $3(4 \%)$ \\
\hline $\begin{array}{l}\text { Beliefs: vaccines \& } \\
\text { immunity }\end{array}$ & $\begin{array}{l}\text { Beliefs about how } \\
\text { immunity occurs, } \\
\text { the role of } \\
\text { vaccines in } \\
\text { immunity, or } \\
\text { about vaccines } \\
\text { themselves }\end{array}$ & $\begin{array}{l}\text { Vaccinated: "She was attending preschool } \\
\text { and colds seemed to circulate from one } \\
\text { child to another. I did it to give her added } \\
\text { immune protection." (this comment also } \\
\text { coded as Beliefs: child) }\end{array}$ & & \\
\hline
\end{tabular}


Table IV. Continued

\begin{tabular}{|c|c|c|c|c|}
\hline \multirow[b]{2}{*}{ Theme } & \multirow[b]{2}{*}{ Description } & \multirow[b]{2}{*}{ Sample quotes } & \multicolumn{2}{|c|}{ Theme frequency among: } \\
\hline & & & $\begin{array}{l}\text { Participants who } \\
\text { vaccinated their } \\
\text { child against flu } \\
\quad(n=44)\end{array}$ & $\begin{array}{l}\text { Participants who did } \\
\text { not vaccinate } \\
\text { their child against } \\
\text { flu }(n=70)\end{array}$ \\
\hline & & $\begin{array}{l}\text { Did not vaccinate: "I believe in the power } \\
\text { of the immune system. If my child gets } \\
\text { the flu then she will develop the } \\
\text { antibodies to prevent it in the future. A } \\
\text { vaccine is no sure way of preventing the } \\
\text { varying strains of the flu. In my } \\
\text { experience the perpetual vaccination } \\
\text { process only makes for stronger viruses } \\
\text { that are more resistant in the future." } \\
\text { (this comment also coded as Beliefs: } \\
\text { child) } \\
\text { Did not vaccinate: "I have always felt the } \\
\text { flu vaccine was unnecessary. A long time } \\
\text { ago my pediatrician told me he didn't } \\
\text { think it was necessary and since then I } \\
\text { have never changed my mind. My } \\
\text { concern has always been that although } \\
\text { they vaccinate against the flu strain- } \\
\text { they don't know which one will hit during } \\
\text { that year so it can't vaccinate against the } \\
\text { current flu outbreak." } \\
\text { Vaccinated: "I believe the vaccine does } \\
\text { help prevent the flu, and have seen it } \\
\text { myself where I was vaccinated, my wife } \\
\text { wasn't, and she got the flu and I didn't. } \\
\text { And that makes me even more } \\
\text { determined to get the flu shots." }\end{array}$ & $8(18 \%)$ & $27(39 \%)$ \\
\hline Logistics & $\begin{array}{l}\text { Comments that demo } \\
\text { circumstances on hi } \\
\text { participant's child a }\end{array}$ & $\begin{array}{l}\text { d the influence of the participant's } \\
\text { r decision to vaccinate or not vaccinate the } \\
\text { lu }\end{array}$ & $4(9 \%)$ & $28(40 \%)$ \\
\hline $\begin{array}{l}\text { Logistics that } \\
\text { interfered }\end{array}$ & $\begin{array}{l}\text { Logistics that } \\
\text { actively interfered } \\
\text { with vaccination }\end{array}$ & $\begin{array}{l}\text { Did not vaccinate: "I honestly couldn't } \\
\text { afford it." } \\
\text { Did not vaccinate: "I did not take him to } \\
\text { get the flu vaccine because it was difficult } \\
\text { to take off of work to bring him." } \\
\text { Did not vaccinate: "I mentioned it to his } \\
\text { doctor but they said they didn't have any. } \\
\text { I intended to bring him back but didn't } \\
\text { get around to it." }\end{array}$ & Not applicable & $11(16 \%)$ \\
\hline $\begin{array}{l}\text { Logistics that failed } \\
\text { to help }\end{array}$ & $\begin{array}{l}\text { Logistics that failed } \\
\text { to help } \\
\text { vaccination but } \\
\text { did not actively } \\
\text { interfere }\end{array}$ & $\begin{array}{l}\text { Did not vaccinate: "Normally they do the } \\
\text { vaccines at school and for some reason } \\
\text { they did not this year. ... We honestly } \\
\text { just didn't think about the vaccine on our } \\
\text { own since it is normally something the } \\
\text { school does." } \\
\text { Did not vaccinate: "Honestly, we were so } \\
\text { busy that I just forgot. Nothing else. Not } \\
\text { my finest moment as a parent but } \\
\text { sometimes it happens." }\end{array}$ & Not applicable & $17(24 \%)$ \\
\hline
\end{tabular}


Table IV. Continued

\begin{tabular}{|c|c|c|c|c|}
\hline \multirow[b]{2}{*}{ Theme } & \multirow[b]{2}{*}{ Description } & \multirow[b]{2}{*}{ Sample quotes } & \multicolumn{2}{|c|}{ Theme frequency among: } \\
\hline & & & $\begin{array}{l}\text { Participants who } \\
\text { vaccinated their } \\
\text { child against flu } \\
(n=44)\end{array}$ & $\begin{array}{c}\text { Participants who did } \\
\text { not vaccinate } \\
\text { their child against } \\
\text { flu }(n=70)\end{array}$ \\
\hline $\begin{array}{l}\text { Logistics that } \\
\text { helped }\end{array}$ & $\begin{array}{l}\text { Logistics that } \\
\text { actively helped } \\
\text { with vaccination }\end{array}$ & $\begin{array}{l}\text { Vaccinated: "We got them the vaccine } \\
\text { because it was offered at Walgreens [a } \\
\text { large pharmacy chain in the U.S.]. I did } \\
\text { notice that they were not sick as often } \\
\text { this winter as they have been in the past." } \\
\text { Vaccinated: "My child got the flu vaccine } \\
\text { mainly because it is a requirement to } \\
\text { attend public school districts, but I also } \\
\text { wanted to prevent all the nasty little } \\
\text { germs that children come home with } \\
\text { from making my household sick too." } \\
\text { (also coded as Beliefs: family) }\end{array}$ & $4(9 \%)$ & Not applicable \\
\hline
\end{tabular}

Table V. Themes (Follow-Up Survey)

\begin{tabular}{lccccc}
\hline & & & \multicolumn{2}{c}{ Themes in response } \\
\cline { 5 - 6 } $\begin{array}{l}\text { Intended to have child } \\
\text { vaccinated against flu }\end{array}$ & $\begin{array}{c}\text { Had child vaccinated } \\
\text { against flu }\end{array}$ & $n$ & Beliefs only & Logistics only & Beliefs and logistics \\
\hline No & No & 40 & $30(75 \%)$ & $6(15 \%)$ & $4(10 \%)$ \\
No & Yes & 6 & $6(100 \%)$ & $0(0 \%)$ & $0(0 \%)$ \\
Yes & No & 29 & $11(38 \%)$ & $17(59 \%)$ & $1(3 \%)$ \\
Yes & Yes & 37 & $33(89 \%)$ & $2(5 \%)$ & $2(5 \%)$ \\
\hline
\end{tabular}

used both a simple interface and a simple underlying model. Further research is needed to investigate whether, for example, more strategically designed risk communication, more complex models, or theoretically-based interfaces designed to support more aspects of the decision-making process ${ }^{(29)}$ might have different effects. Another promising avenue will involve investigating whether implementing these kinds of interventions as part of a clinical encounter using a shared decision-making approach $^{(6)}$ might address challenges by supporting parents and guardians in discussing their questions with a trusted health-care professional.

\subsection{Limitations}

This study has several limitations. First, participants were recruited from an online pool of potential survey participants and thus may not be representative of the broader population. We had difficulty recruiting enough participants who met our inclusion and exclusion criteria, and the rate of participation in the follow-up study was lower than our original aim of $50 \%$. The long delay between the original survey and the follow-up survey may have contributed to the difficulty in retention. In addition, because recruitment was done via MTurk, it was difficult to recontact participants. Such difficulties in retention will need to be addressed in future studies of this nature. Because of the smaller sample than planned for the follow-up study, its results must be interpreted with caution.

Second, the risk and benefit information and decision attributes used in the values clarification exercise consisted only of those for which data were available for risk estimates. This means that other potentially important decision attributes, for example, the out-of-pocket cost of the vaccine to a given participant or the time required to take the child to a location to receive the vaccine, were not integrated into the risk-benefit information nor the values clarification methods. Our qualitative analysis suggests 
that such barriers are important to at least some people. In addition, the risk estimates are themselves limited by our decision to privilege evidence for which the full text would be freely available to all study participants via a simple click (rather than, for example, a relevant Cochrane review ${ }^{(58)}$ ) as well as by the inherent uncertainty within scientific evidence.

Third, the original survey used values congruence between stated values and vaccination intentions as a secondary outcome. The follow-up survey used a measure of informed choice that includes the criterion that the final decision must be congruent with one's values. Values congruence is a key metric of decision quality ${ }^{(30,31)}$ but measuring it is problematic because the mere act of asking questions about values is a values clarification intervention in and of itself. To avoid this problem to the greatest extent possible, we framed the question very broadlyasking about participants' opinions of the risk-benefit balance, not asking directly about their values for different attributes of the options-and placed it near the end of the original survey among fact-based questions to help elicit an immediate answer rather than a contemplative process. However, including this question may have reduced our ability to detect any effects of the experimental factor Values Clarification in the follow-up study of actual vaccination behavior.

Fourth and finally, as noted above, in our experimental conditions, we presented the information in as neutral and balanced a way as possible, in keeping with international standards for patient decision aids. ${ }^{(59)}$ Our experimental methods made no universal recommendations and deliberately did not emphasize the importance of vaccination. Further, in the original survey, we provided resources-such as further information and a link to locations to get a flu vaccine-to all participants, not just those in the intervention groups. These features combined with the smaller original sample size than planned and the low response rate in the follow-up study meant that our ability to detect effects of our experimental factors on vaccination status and to incorporate other potential moderators into our models were limited. The promising results obtained despite these challenges suggest that further work is needed to build upon this preliminary study.

\subsection{Conclusions}

Current standard methods of providing parents and guardians with information about childhood influenza immunization may be improved by providing absolute estimates of risks and benefits. Further, to support parents and guardians in making informed choices about whether or not to vaccinate their children against influenza, it may not be enough to present information about risks and benefits well: we may also need to help people align their choices with their values. Higher intentions to vaccinate were associated with our experimental methods, and intentions significantly predicted rates of vaccination. Although there was no association between our experimental methods and rates of vaccination in this small sample, the results of this study are encouraging for future research.

There is a philosophical tension between the potential public good of vaccination and the individualized principles of autonomy and informed choice. Applying an approach that incorporates the detailed communication of risk and benefits of vaccination and an explicit method to help people understand how their values are connected to their decision options is different from many public health approaches to vaccination. Our results support the contention that methods of risk communication and values clarification that have been shown to be helpful in other clinical contexts may also be helpful in the context of vaccination. Such techniques may hold the potential to serve both sides of the philosophical tension by supporting individual informed choice while also potentially leading to higher vaccination uptake.

\section{ACKNOWLEDGMENTS}

Dr. Witteman received a small honorarium and travel funds from the Harvard Center for Risk Analysis to present portions of this work at a conference hosted by the Center in 2014. Dr. Witteman is also supported by a Research Scholar Junior 1 career development award from the Fonds de recherche du Québec - Santé. Dr. Zikmund-Fisher was supported by a career development award from the American Cancer Society (MRSG-06-130-01-CPPB). The funding agreements ensured the authors' independence in designing the study, in collecting, analyzing, and interpreting the data, and in writing the article. The authors gratefully acknowledge the contribution of Mark Dickson, who programmed the interactive elements for this study. The authors also thank attendees of the Risk, Perception, and Response conference hosted by the Harvard Center for Risk Analysis in March 2014. The constructive comments, thought-provoking presentations, and lively debate 
among conference attendees helped to shape this article. Finally, the authors would like to thank the two anonymous reviewers. The reviewers provided very thoughtful, constructive comments and helped us improve this article.

\section{REFERENCES}

1. Weinstein ND. Perceived probability, perceived severity, and health-protective behavior. Health Psychology, 2000; 19(1):65-74.

2. Slovic P, Peters EM, Finucane ML, MacGregor DG. Affect, risk, and decision making. Health Psychology, 2005; 24(4 Suppl):S35-S40.

3. Amsterlaw J, Zikmund-Fisher BJ, Fagerlin A, Ubel PA. Can avoidance of complications lead to biased healthcare decisions? Judgment and Decision Making, 2006; 1(1):64-75.

4. Witteman HO, Ubel PA, Angott AM, Fuhrel-Forbis A, Fagerlin A, Zikmund-Fisher BJ. Colostomy Is Better Than Death, but a $4 \%$ Chance of Death Might Be Better Than a 4\% Chance Of Colostomy: Why People Make Choices Seemingly at Odds with Their Stated Preferences. The 32nd Annual Meeting of the Society for Medical Decision Making. Toronto, Canada, 2010. Abstract available at: https://smdm. confex.com/smdm/2010on/webprogram/Paper5852.html.

5. Stacey D, Legare F, Col NF, Bennett CL, Barry MJ, Eden KB, Holmes-Rovner M, Llewellyn-Thomas HA, Lyddiatt A, Thomson R, Trevena LJ, Wu JH. Decision aids for people facing health treatment or screening decisions. Cochrane Database of Systematic Reviews, 2014;CD001431.

6. Legare F, Witteman HO. Shared decision making: Examining key elements and barriers to adoption into routine clinical practice. Health Affairs, 2013; 32(2):276-284.

7. Hawley ST, Zikmund-Fisher B, Ubel P, Jancovic A, Lucas T, Fagerlin A. The impact of the format of graphical presentation on health-related knowledge and treatment choices. Patient Education and Counseling, 2008; 73(3):448-455.

8. Zikmund-Fisher BJ, Fagerlin A, Ubel PA. Improving understanding of adjuvant therapy options by using simpler risk graphics. Cancer, 2008; 113(12):3382-3390.

9. Witteman HO, Scherer LD, Angott AM, Ubel PA, Dickson M, Holtzman LG, Exe NL, Zikmund-Fisher BJ. Hold My Hand: Explicitly Showing Tradeoffs and Fit Between Values and Options Helps People Make Choices More Concordant with Their Stated Values. The 34th Annual Meeting of the Society for Medical Decision Making. Phoenix, AZ, 2012. Abstract available at: https:// smdm.confex.com/smdm/2012az/webprogram/Paper7417.html.

10. Larson HJ, Cooper LZ, Eskola J, Katz SL, Ratzan S. Addressing the vaccine confidence gap. Lancet, 2011; 378(9790):526535.

11. Wroe AL, Turner N, Owens RG. Evaluation of a decision making aid for parents regarding childhood immunizations. Health Psychology, 2005; 24(6):539-547.

12. Downs JS, deBruin WB, Fischhoff B. Parents' vaccination comprehension and decisions. Vaccine, 2008; 26(12):15951607.

13. Brunson EK. The impact of social networks on parents' vaccination decisions. Pediatrics, 2013; 131(5):e1397-e1404.

14. Betsch C, Renkewitz F, Betsch T, Ulshofer C. The influence of vaccine-critical websites on perceiving vaccination risks. Journal of Health Psychology, 2010; 15(3):446-455.

15. Witteman HO, Zikmund-Fisher BJ. The defining characteristics of Web 2.0 and their potential influence in the online vaccination debate. Vaccine, 2012; 30(25):3734-3740.

16. Brown KF, Kroll JS, Hudson MJ, Ramsay M, Green J. Factors underlying parental decisions about combination childhood vaccinations including MMR: A systematic review. Vaccine, 2010; 28:4235-4248.

17. Smith PJ, Humiston SG, Marcuse EK, Zhao Z, Dorell CG, Howes C, Hibbs B. Parental delay or refusal of vaccine doses, childhood vaccination coverage at 24 months of age, and the health belief model. Public Health Reports, 2011; 126(Suppl 2):135.

18. Eberth JM, Kline KN, Moskowitz DA, Montealegre JR, Scheurer ME. The role of media and the Internet on vaccine adverse event reporting: A case study of human papillomavirus vaccination. Journal of Adolescent Health, 2014; 54(3):289-295.

19. Dubé E, Laberge C, Guay M, Bramadat P, Roy R, Bettinger JA. Vaccine hesitancy: An overview. Human Vaccines and Immunotherapeutics, 2014; 9(8):1763-1773.

20. Gahr P, DeVries AS, Wallace G, Miller C, Kenyon C, Sweet K, Martin K, White K, Bagstad E, Hooker C, Krawczynski G, Boxrud D, Liu G, Stinchfield P, LeBlanc J, Hickman C, Bahta L, Barskey A, Lynfield R. An outbreak of measles in an undervaccinated community. Pediatrics, 2014; 134:e220-e288.

21. Hambidge SJ, Newcomer SR, Narwaney KJ, Glanz JM, Daley MF, Xu S, Shoup JA, Rowhani-Rahbar A, Klein NP, Lee GM, Nelson JC, Lugg M, Naleway AL, Nordin JD, Weintraub E, DeStefano F. Timely versus delayed early childhood vaccination and seizures. Pediatric, 2014; 133(6):e1492-e1499.

22. Hoen AG, Buckeridge DL, Charland KML, Mandl KD, Quach C, Brownstein JS. Effect of expanded US recommendations for seasonal influenza vaccination: Comparison of two pediatric emergency departments in the United States and Canada. Canadian Medical Association Journal, 2011; 183(13):E1025-E1032.

23. CDC Reports About 90 Percent of Children Who Died from Flu This Season Not Vaccinated. Centers for Disease Control and Prevention, National Center for Immunization and Respiratory Diseases (NCIRD), 2013. Available at: http://www.cdc.gov/flu/spotlights/children-flu-deaths.htm.

24. E Fiore A, Epperson S, Perrotta D, Bernstein H, Neuzil K. Expanding the recommendations for annual influenza vaccination to school-age children in the United States. Pediatrics, 2012; 129(Supplement):S54-S62.

25. Children, the Flu, and the Flu Vaccine, 2013. from: http://www.cdc.gov/flu/protect/children.htm.

26. Gust DA, Darling N, Kennedy A, Schwartz B. Parents with doubts about vaccines: Which vaccines and reasons why. Pediatrics, 2008; 122(4):718-725.

27. Flood EM, Rousculp MD, Ryan KJ, Beusterien KM, Divino VM, Toback SL, Sasané M, Block SL, Hall MC, Mahadevia PJ. Parents' decision making regarding vaccinating their children against influenza: A web-based survey. Clinical Therapeutics, 2010; 32(8):1448-1467.

28. Fagerlin A, Pignone MP, Abhyankar P, Col N, FeldmanStewart D, Gavaruzzi T, Kryworuchko J, Levin CA, Pieterse AH, Reyna V, Stiggelbout A, Scherer LD, Wills C, Witteman HO. Clarifying values: An updated review. BMC Medical Informatics and Decision Making, 2013; 13(Suppl 2):S8.

29. Pieterse $\mathrm{AH}$, deVries $M$, Kunneman $M$, Stiggelbout AM, Feldman-Stewart D. Theory-informed design of values clarification methods: A cognitive psychological perspective on patient health-related decision making. Social Science and Medicine, 2013; 77:156-163.

30. Marteau TM, Dormandy E, Michie S. A measure of informed choice. Health Expectations, 2001; 4(2):99-108.

31. Michie S, Dormandy E, Marteau TM. The multi-dimensional measure of informed choice: A validation study. Patient Education and Counseling, 2002; 48(1):87-91.

32. Buhrmester M, Kwang T, Gosling SD. Amazon's Mechanical Turk: A new source of inexpensive, yet high-quality, data? Perspectives on Psychological Science, 2011; 6(1): 3-5. 
33. Prosser LA, Bridges CB, Uyeki TM, Hinrichsen VL, Meltzer MI, Molinari N-AM, Schwartz B, Thompson WW, Fukuda K, Lieu TA. Health benefits, risks, and cost-effectiveness of influenza vaccination of children. Emerging Infectious Disease, 2006; 12(10):1548-1558.

34. Centers for Disease Control and Prevention. InfluenzaAssociated Pediatric Deaths-United States, September 2010-August 2011. MMWR, 2011; 60:1233-1268. Centers for Disease Control and Prevention, National Center for Immunization and Respiratory Diseases (NCIRD), 2011;1-36.

35. Kwong JC, Vasa PP, Campitelli MA, Hawken S, Wilson K, Rosella LC, Stukel TA, Crowcroft NS, McGeer AJ, Zinman L, Deeks SL. Risk of Guillain-Barré syndrome after seasonal influenza vaccination and influenza health-care encounters: A self-controlled study. Lancet Infectious Diseases, 2013; 13:769-776.

36. Trevena LJ, Zikmund-Fisher BJ, Edwards A, Gaissmaier W, Galesic M, Han PKJ, King J, Lawson ML, Linder SK, Lipkus I, Ozanne E, Peters EM, Timmermans D, Woloshin S. Presenting quantitative information about decision outcomes: A risk communication primer for patient decision aid developers. BMC Medical Informatics and Decision Making, 2013; 13(Suppl 2):S7.

37. Zikmund-Fisher BJ, Fagerlin A, Ubel PA. A demonstration of "less can be more" in risk graphics. Medical Decision Making, 2010; 30(6):661-671.

38. Fagerlin A, Pignone MP, Abhyankar P, Col NF, FeldmanStewart D, Kryworuchko J, Levin C, Pieterse AH, Reyna VF, Scherer LD, Stiggelbout AM, Wills CE, Witteman HO. Clarifying and Expressing Values. Ottawa: International Patient Decision Aids Standards, 2013.

39. Reyna VF. A theory of medical decision making and health: Fuzzy trace theory. Medical Decision Making, 2008; 28(6):850-865.

40. Shinall MC, Plosa EJ, Poehling KA. Validity of parental report of influenza vaccination in children 6 to 59 months of age. Pediatrics, 2007; 120(4):e783-e787.

41. Brown C, Clayton-Boswell H, Chaves SS, Prill MM, Iwane MK, Szilagyi PG, Edwards KM, Staat MA, Weinberg GA, Fairbrother G, Hall CB, Zhu Y, Bridges CB, New Vaccine Surveillance Network (NVSN). Validity of parental report of influenza vaccination in young children seeking medical care. Vaccine. 2011; 29(51):9488-9492.

42. Song G. Understanding public perceptions of benefits and risks of childhood vaccinations in the United States. Risk Analysis, 2013; 34:541-555.

43. Microsoft Excel 2008 for Mac, 12th ed. Redmond, CA: Microsoft.

44. R Development Core Team. R: A language and environment for statistical computing, 2nd ed. Vienna, Austria: R Foundation for Statistical Computing.

45. CDC-Centers for Disease Control and Prevention. Flu Vaccination Coverage: United States, 2013-14 Influenza Season, 2014. Available at: http://www.cdc.gov/flu/pdf/ fluvaxview/vax-coverage-1314estimates.pdf.

46. Lu P-J, O'Halloran A, Ding H, Williams WW, Bridges CB, Kennedy ED. National and state-specific estimates of place of influenza vaccination among adult populations-United States, 2011-12 influenza season. Vaccine, 2014; 32(26):31983204.

47. Goad JA, Taitel MS, Fensterheim LE, Cannon AE. Vaccinations administered during off-clinic hours at a national community pharmacy: Implications for increasing patient access and convenience. Annals of Family Medicine, 2013; 11(5):429_ 436.

48. Humiston SG, Schaffer SJ, Szilagyi PG, Long CE. Seasonal influenza vaccination at school: A randomized controlled trial. American Journal of Preventive Medicine, 2014; 46(1):1-9.

49. Campitelli MA, Inoue M, Calzavara AJ, Kwong JC, Guttmann A. Low rates of influenza immunization in young children under Ontario's universal influenza immunization program. Pediatrics, 2012; 129(6):e1421-e1430.

50. Jackson C, Cheater FM, Peacock R, Leask J, Trevena LJ. Evaluating a web-based MMR decision aid to support informed decision making by UK parents: A before-and-after feasibility study. Health Education Journal, 2010; 69(1):74-83.

51. Shourie S, Jackson C, Cheater FM, Bekker HL, Edlin R, Tubeuf S, Harrison W, McAleese E, Schweiger M, Bleasby B, Hammond L. A cluster randomised controlled trial of a web based decision aid to support parents' decisions about their child's measles mumps and rubella (MMR) vaccination. Vaccine, 2013; 31(50):6003-6010.

52. Wallace C, Leask J, Trevena LJ. Effects of a web based decision aid on parental attitudes to MMR vaccination: A before and after study. BMJ, 2006; 332(7534):146-149.

53. Opel DJ, Heritage J, Taylor JA, Mangione-Smith R, Salas HS, DeVere V, Zhou C, Robinson JD. The architecture of provider-parent vaccine discussions at health supervision visits. Pediatrics, 2013; 132(6):1037-1046.

54. Healy CM, Pickering LK. How to communicate with vaccinehesitant parents. Pediatrics, 2011; 127(Suppl 1):S127-S133.

55. Shelby A, Ernst K. Story and science: How providers and parents can utilize storytelling to combat anti-vaccine misinformation. Human Vaccines and Immunotherapeutics, 2013; 9(8):1795-1801.

56. Ajzen I. The theory of planned behavior. Organizational Behavior and Human Decision Processes, 1991; 50(2):179-211.

57. Williams SE, Rothman RL, Offit PA, Schaffner W, Sullivan M, Edwards KM. A randomized trial to increase acceptance of childhood vaccines by vaccine-hesitant parents: A pilot study. Academic Pediatrics, 2013; 13(5):475-480.

58. Jefferson T, Rivetti A, Di Pietrantonj C, Demicheli V, Ferroni E. Vaccines for preventing influenza in healthy children. Cochrane Database of Systematic Reviews, 2012; 8:CD004879

59. Abhyankar P, Volk RJ, Blumenthal-Barby J, Bravo P, Buchholz A, Ozanne E, Vidal DC, Col N, Stalmeier P. Balancing the presentation of information and options in patient decision aids: An updated review. BMC Medical Informatics and Decision Making, 2013; 13(Suppl 2):S6.

\section{SUPPORTING INFORMATION}

Additional Supporting Information may be found in the online version of this article at the publisher's website:

Appendix 1: Pages Showing Control and Risk Communication Intervention

Appendix 2: Follow-up Survey Knowledge Questions 